\title{
Changes in reflectance anisotropy of wheat crop during different phenophases
}

\author{
Manoj M. Lunagaria* and Haridas R. Patel \\ Department of Agricultural Meteorology, BACA, AAU, Anand 388110, India
}

Received July 26, 2016; accepted March 29, 2017

\begin{abstract}
A b s t r a c t. The canopy structure of wheat changes significantly with growth stages and leads to changes in reflectance anisotropy. Bidirectional reflectance distribution function characterises the reflectance anisotropy of the targets, which can be approximated. Spectrodirectional reflectance measurements on wheat crop were acquired using a field goniometer system. The bidirectional reflectance spectra were acquired at 54 view angles to cover the hemispheric span up to $60^{\circ}$ view zenith. The observations were made during early growth stages till maturity of the crop. The anisotropy was not constant for all wavelengths and anisotropic factors clearly revealed spectral dependence, which was more pronounced in near principal plane. In near infrared, wheat canopy expressed less reflectance anisotropy because of higher multiple scattering. The broad hotspot signature was noticeable in reflectance of canopy whenever view and solar angles were close. Distinct changes in bidirectional reflectance distribution function were observed during booting to flowering stages as the canopy achieves more uniformity, height and head emergence. The function clearly reveals bowl shape during heading to early milking growth stages of the crop. Late growth stages show less prominent gap and shadow effects. Anisotropy index revealed that wheat exhibits changes in reflectance anisotropy with phenological development and with spectral bands.

K e y w o r d s: BRDF, reflectance anisotropy, wheat, spectrodirectional measurement, goniometer
\end{abstract}

\section{INTRODUCTION}

Vegetation canopies do not reflect equal radiance in all view directions as they behave as anisotropic reflector. The anisotropy arises because of three dimensional canopy and landscape structure, leaf optical properties and soil reflectance (Lobell et al., 2002). This fact is usually neglected and vegetation surfaces considered as an isotropic reflector in remote sensing studies. Bidirectional reflectance distribution function (BRDF) determines the degree of anisotropy of the surface reflective properties (Nicodemus et al., 1977). The magnitude of BRDF effects can lead to large

*Corresponding author e-mail: mlunagaria@gmail.com errors, when observing the phenological evolution of vegetation on a regional scale (Zhang et al., 2014; Van Beek et al., 2016; Gutman, 1987; Roujean et al., 1992). Therefore, remote sensing data need to be normalised or corrected using the BRDF of the crop canopy. Multi-angular remote sensing captures anisotropy in reflectance that arises from canopy structure, illumination geometry and viewing geometry. There are many operating multi-angular earth observing remote sensors and their number will increase in the future. But estimation of BRDF from a satellite observation is difficult (Luo et al., 2005) and satellite sensors do not provide simultaneous reflectance in all viewing directions. Laboratory measurements provide a better control of the illumination conditions but the artificial light source shows a conical rather than directional geometry, leading to non-homogeneity of the illuminated area (Schopfer et al., 2008). The field measurement of bidirectional reflectance factor has the advantage that the target is left in its natural condition under natural illumination of the sun. So, in situ measurements are essential for the validation of off nadir remote sensing image products and canopy BRDF models. With a view to the importance of field measurements, many bidirectional reflectance factor (BRF) sampling devices for field and natural illumination conditions have been designed by some research groups (Bourgeois et al. 2006; Landis and Aber, 2007; Schopfer et al., 2008; Sridhar et al., 2009; Susaki et al., 2004). A majority of them resemble the well documented Swiss field goniometer system (FIGOS) (Sandmeier and Itten, 1999).

The objective of the present study was to characterise the change in hyperspectral BRDF of the wheat canopy with change in phenophases during the developmental cycle of wheat, using spectrodirectional measurements acquired with a field goniometer system. 


\section{MATERIALS AND METHODS}

The experimental site $\left(22.538^{\circ} \mathrm{N}\right.$ Latitude, $72.981^{\circ} \mathrm{E}$ Longitude, $45.1 \mathrm{~m} \mathrm{MSL}$ ) for the acquisition of field measurements is located near the Agrometeorological observatory of AAU, Anand, Gujarat (India). Anand is located in the Middle Gujarat Agro-Climatic Zone of Gujarat state, characterised by rainfall ranging from 750 to $1000 \mathrm{~mm}$ and average temperatures ranging from 19.8 to $33.4^{\circ} \mathrm{C}$ ( $\mathrm{T}$ min to $\mathrm{T}$ max). Climate of Anand region is a mixture of subtropical and semi-arid climate. Moderately cool weather generally commences around November which is the ideal time in the region for wheat sowing. In winter, January registers the lowest normal daily and monthly minimum temperatures in a year having normal monthly minimum temperature of $15.6^{\circ} \mathrm{C}$, with monthly mean temperature of $23.2^{\circ} \mathrm{C}$. Weather starts getting warmer with the onset of March which marks the onset of summer. At onset of summer, wheat crop achieve maturity in the region.

The weather parameters (mainly wind) can alter the structure and orientation of the vegetation surfaces like tall grasslands and crop fields (Lord et al., 1985). Thus, Sandmeier (2000) suggested to monitor wind conditions as well as air temperature and relative humidity during experimental period which may affect the target BRDF. Weather parameters specific to the period of this experiment are depicted in Fig. 1. The weather parameters during wheat crop growth period mostly followed the normal pattern, with some variation and very few extremes.

The soil of the experiment site was is sandy loam in nature (Alluvial soil, Orchrespt). It is light brown, very deep, well drained and has fairly good moisture retention capacity. The soil profile is uniform up to a depth of $120 \mathrm{~cm}$.

A field goniometer similar to field goniometer system (FIGOS) (Sandmeier and Itten, 1999) has been installed by Space Applications Centre (ISRO) (Sridhar et al. 2009) at the experimental site. The goniometer consists of circular azimuthal rail of $4 \mathrm{~m}$ diameter and a semi-circular zenith arc mounted on the azimuthal rail (Fig. 2).

The instrument has the capability to measure the angles of the sensor -90 to $+90^{\circ}$ for zenith plane (with $0^{\circ}$ as nadir) and 0 to $360^{\circ}$ for azimuthal plane. Angular position of the spectroradiometer mounted on the zenith arch can be fixed by chain pulley mechanism for zenith angle setting and rotation of the zenith arc along the azimuthal ring. A moving supporting arm made of an iron bar is fixed to hold the Spectralon ${ }^{\circledR}$ reflectance standard during the measurements.

The experiment was carried out on wheat (Triticum aestivum L.) crop with cultivar GW-496. This cultivar is widely grown in Gujarat state of India. It is a two-gene high yielding dwarf variety having semi erect and early growth habit, good tillering capacity with green foliage, semi early in maturity (105-113 days). The heads of the cultivar are medium, dense, with glabrous white glumes.
The row effect is reported to be prominent in BRF observations of agricultural crops due to azimuthal asymmetry (Lucht and Roujean, 2000). To achieve azimuthal symmetry wheat was sown in concentric rows under the field goniometer (i.e. circular plot of $\sim 5 \mathrm{~m}$ diameter) with row spacing of $22.5 \mathrm{~cm}$. The seed rate and fertiliser doses were maintained as per the recommendation, by computing the amount for each row individually. The crop growth season was November 2011 to March 2012, during which the experiment was conducted. Cultural practices and irrigations were adopted as per recommended package of practices for the locality and cultivar.

Spectral reflectance measurements were acquired using an analytical spectral devices (ASD) FieldSpec HH spectroradiometer (Inc., USA) mounted on the field goniometer system. The ASD FieldSpec HH sensor operated with a $3.5^{\circ}$ IFOV and data sampling in a spectral range from 325 to $1075 \mathrm{~nm}$ at spectral resolution of $1.0 \mathrm{~nm}$ A Spectralon ${ }^{\circledR}$ panel (30 $330 \mathrm{~cm}$ dimension) was used as a reflectance standard surface. The resolutions of $30^{\circ}$ and $15^{\circ}$ in azimuth $(\varphi)$ and zenith $(\theta)$ angles, respectively, were used for the reflectance measurement for full hemispheric coverage (Fig. 3). At each azimuth $(\varphi)$ and zenith $(\theta)$ angular combination point of hemisphere 3 reflectance spectra were collected. The BRF from the exact solar principal plane were not measured to avoid self-shadowing on the canopy by the zenith arc and spectroradiometer. With this measurement protocol, a total of 162 spectra $(54 \times 3)$ were collected during each observation cycle. Spectral measurements were collected around solar noon $(12: 38 \mathrm{~h})$ on clear and haze free days. The spectrodirectional measurements were made from tillering (31 DAS; when canopy achieved complete ground cover) to dough stage (89 DAS). The full set of spectra were acquired in less than $25 \mathrm{~min}$ (Table 1) to avoid significant change in solar position during observations, as movement in the position of illumination source is crucial for data quality.

With IFOV $3.5^{\circ}$, spectroradiometer projects circular GIFOV of $12.22 \mathrm{~cm}$ diameter in nadir position while target is at radius distance of the goniometer. Whereas, with increase in the view zenith angles GIFOV becomes elliptical and its extent increases in the foreword direction. The extent of the GIFOV with different zenith angles is summarised in Table 1 and depicted in Fig. 4. Maximum extent of the GIFOV was $24.5 \mathrm{~cm}$ for $60^{\circ}$ zenith angle for the experiment. Details regarding phenophase, day, time taken for each acquisition, solar position and canopy structure parameters for each measurement cycle are given in Table 2.

Atmospheric conditions must be considered for accurate ground BRDF data interpretation (Deering and Eck, 1987; Sandmeier, 2000). The Microtops II $^{\circledR}$ Sunphotometer was used for the aerosol optical thickness and columnar water vapour $\left(\mathrm{gm} \mathrm{cm}^{-2}\right)$ measurement to assure clear and haze free sky condition during spectrodirectional measurements. The observations on canopy architecture of wheat (Table 2) 

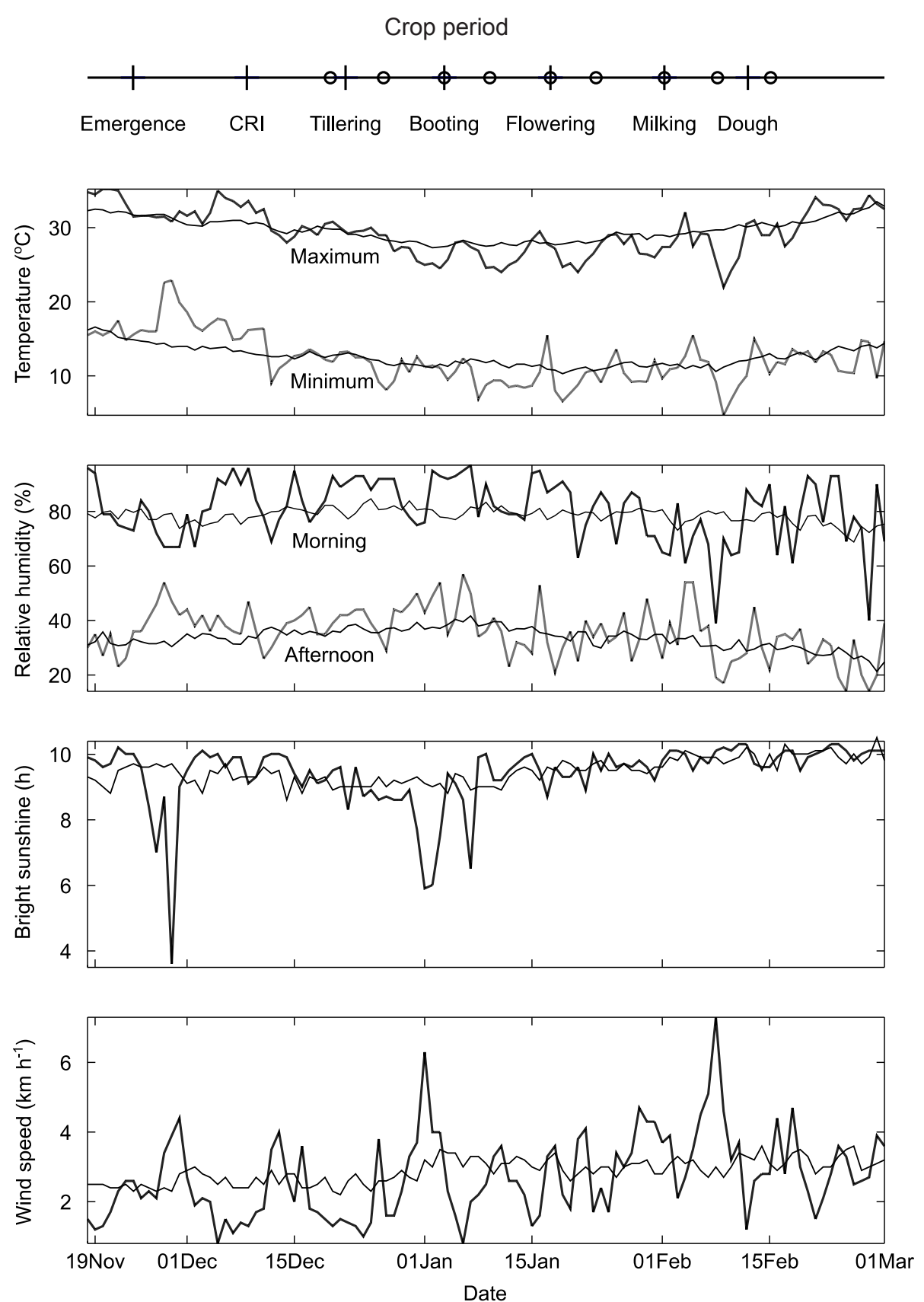

Fig. 1. Weather parameters during field experiment (climatic normals given as thin line; circle indicates day of observation).

were recorded at all phenophases to understand the change in BRDF with canopy architecture. Leaf area index (LAI) and mean tilt angle (MTA) was measured non-destructively using a LAI-2000 Plant Canopy Analyser (LI-COR, Lincoln, Nebraska, USA) with azimuth mask of $180^{\circ}$ view restriction cap. The measurements were acquired during periods near to sunset or sunrise to avoid the interference of direct sunlight. Plant height was measured with a ruler scale. The soil moisture content (Table 2) of the experimental plot under the goniometer was estimated by gravimetric method using soil samples drawn from $0-10 \mathrm{~cm}$ depth.
The software (ASD RS3) of spectroradiometer (ASD FieldSpec $\mathrm{HH}$ ) was configured to capture three reflectance factor measurements at each angle. A complete spectrodirectional set of observations over hemisphere generates a total of $162(54 \times 3)$ files. The files are in binary format and can be accessed only by software ASD ViewSpec. One by one each of these files were converted to ASCII format using this software along with critical data inspection. The converted files were used for further scientific computation and analysis. 


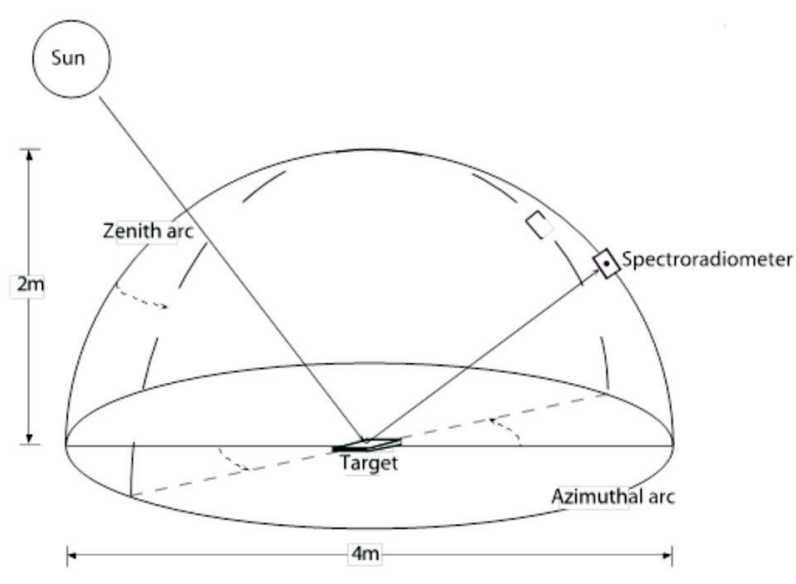

Fig. 2. Schematic of the spectro-goniometer setup.

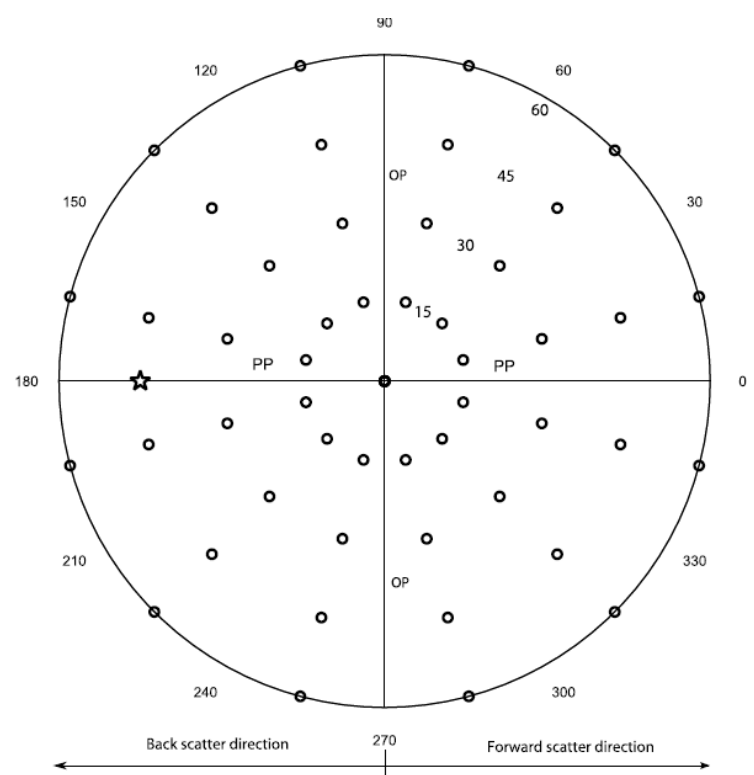

Fig. 3. Projection layout of spectrodirectional measurements over the hemisphere ( $\mathrm{PP}$ - solar principal plane, $\mathrm{OP}$ - orthogonal plane to the $\mathrm{PP}$ - pentagram is the position of sun).

T a b l e 1. Change in GIFOV with view zenith angle

\begin{tabular}{cccc}
\hline & \multicolumn{2}{c}{ Major half axis } & Major axis \\
View zenith & foreword & \\
\cline { 2 - 3 } angle $\left(^{\circ}\right)$ & backward & for & \\
\cline { 2 - 3 } 0 & 6.11 & 6.11 & 12.22 \\
15 & 6.27 & 6.38 & 12.65 \\
30 & 6.93 & 7.18 & 14.12 \\
45 & 8.39 & 8.91 & 17.30 \\
60 & 11.61 & 12.90 & 24.51 \\
\hline
\end{tabular}

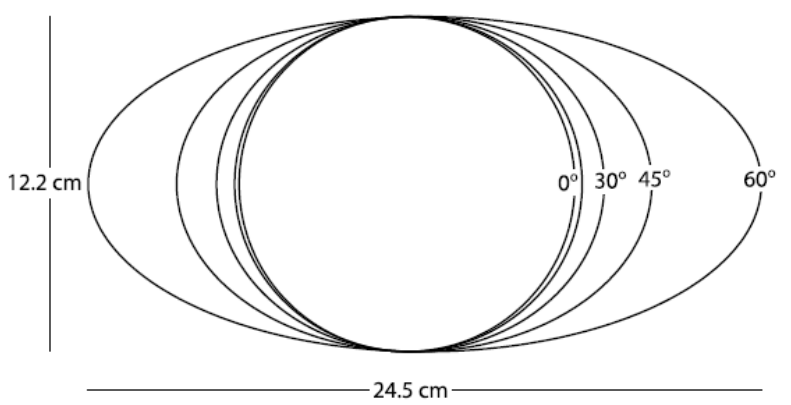

Fig. 4. Extent of ground projected instantaneous field of view (GIFOV) at different view zenith angles.

Since the BRDF of the target cannot be measured directly, it is expressed as the BRDF shape generated by BRF sampling coverage over the hemisphere. The analysis of the spectral variability of the BRDF can be characterised using anisotropy factor (ANIF) and anisotropy index (ANIX).

The BRDF is a ratio of radiance $L\left(\mathrm{Wm}^{-2} \mathrm{sr}^{-1} \mathrm{~nm}^{-1}\right)$ reflected in one direction $\theta_{r}, \varphi_{r}$ to the incident irradiance $\mathrm{E}_{\mathrm{i}}\left(\mathrm{Wm}^{-2} \mathrm{~nm}^{-1}\right)$ from direction $\theta_{i}, \varphi_{i}$. It is a non-measurable quantity as it involves infinitesimally small sensor field of view and incident solid angles. However, in practice we can approximate BRDF of the crop canopy by means of bidirectional reflectance factor (BRF)R. The measurement in the conditions of sensor having sufficiently small IFOV and irradiance predominantly directional is usually expressed as $B R F(R)$. In actual BRF measurements, irradiance $\left(\mathrm{dE}_{\mathrm{i}}\right)$ from a solid angle is not measured directly and estimated by measuring radiance reflected from a Lambertian lossless white reference standard $\left(d L_{r e f}\right)$ with known reflectance characteristics $R_{r e f}$. The spectra obtained using a field goniometer were processed for $R$ as:

$$
\begin{aligned}
R\left(\lambda, \theta_{i}, \varphi_{i}, \theta_{r}, \varphi_{r}\right)= & {\left[\frac{d L_{r}\left(\lambda, \theta_{i}, \varphi_{i}, \theta_{r}, \varphi_{r}\right)}{d L_{r e f}\left(\lambda, \theta_{i}, \varphi_{i}, \theta_{r}, \varphi_{r}\right)}\right] } \\
& R_{r e f}\left(\lambda, \theta_{i}, \varphi_{i}, \theta_{r}, \varphi_{r}\right) .
\end{aligned}
$$

The systematic analysis of wavelength dependence of BRDF effects can be done by normalising BRDF spectra to a reference reflectance signature like nadir reflectance spectra (Middleton, 1992; Sandmeier et al., 1998a).

The anisotropy factor describes the portion of radiation reflected into a specific view direction relative to the nadir reflectance and is sometimes called relative reflectance (Jackson et al., 1990). This is nadir normalisation of BRF data:

$$
\operatorname{ANIF}\left(\lambda, \theta_{i}, \varphi_{i}, \theta_{r}, \varphi_{r}\right)=\frac{R\left(\lambda, \theta_{i}, \varphi_{i}, \theta_{r}, \varphi_{r}\right)}{R_{0}\left(\lambda, \theta_{i}, \varphi_{i}\right)},
$$

where: $R$ is bidirectional reflectance factor, $R_{0}$ is nadir reflectance factor, $\lambda$ is wavelength, $\theta$ is zenith angle, $\varphi$ is azimuth angle, subscripts $i$ and $r$ are illumination and view angles. 
T a b l e 2. Phenophase, time of spectrodirectional measurements with illumination geometry, soil moisture status and canopy parameters

\begin{tabular}{|c|c|c|c|c|c|c|c|c|c|}
\hline \multirow{2}{*}{ No. } & \multirow{2}{*}{ Phenophase } & \multirow{2}{*}{ Date } & \multirow{2}{*}{$\begin{array}{l}\text { Time } \\
\text { taken } \\
(\mathrm{min})\end{array}$} & \multicolumn{2}{|c|}{ Illumination geometry } & \multirow{2}{*}{ LAI } & \multirow{2}{*}{ MTA } & \multirow{2}{*}{$\begin{array}{l}\text { Height } \\
(\mathrm{cm})\end{array}$} & \multirow{2}{*}{$\begin{array}{c}\text { Soil } \\
\text { moisture } \\
(\%)\end{array}$} \\
\hline & & & & $\varphi_{i}$ & $\theta_{i}$ & & & & \\
\hline 1 & Tillering & 26.12.2011 & 24 & $177.6-185.0$ & $45.9-46.1$ & 3.93 & 48 & 46 & 4.2 \\
\hline 2 & Booting & 03.01 .2012 & 20 & $180.7-187.2$ & $45.4-45.7$ & 4.49 & 52 & 53 & 6.5 \\
\hline 3 & Heading & 17.01.2012 & 18 & $167.4-173.4$ & $44.3-43.6$ & 4.71 & 56 & 85 & 3.5 \\
\hline 4 & Flowering & 23.01 .2012 & 18 & $171.7-178.3$ & $42.5-42.1$ & 4.96 & 55 & 95 & 9.0 \\
\hline 5 & Early milking & 31.01 .2012 & 19 & $169.7-176.8$ & $41.3-40.7$ & 4.52 & 58 & 96 & 2.8 \\
\hline 6 & Late milking & 08.02 .2012 & 19 & $159.0-165.6$ & $40.1-38.8$ & 4.10 & 58 & 96 & 3.1 \\
\hline 7 & Dough & 15.02 .2012 & 17 & 182.4-189.6 & $35.4-35.8$ & 3.35 & 58 & 96 & 6.4 \\
\hline
\end{tabular}

The ANIF values allow separation of spectral BRDF effects from spectral signature of the target.

Anisotropy index is the overall estimate of reflectance anisotropy and can be used to compare spectral BRDF of different surfaces. It is defined as the ratio of the maximum and minimum bidirectional reflectance factors acquired in the solar principal plane (or defined azimuth plane) in a spectral band (Sandmeier et al., 1998a):

$$
\operatorname{ANIX}(\lambda)=\frac{R_{\max }(\lambda)}{R_{\min }(\lambda)}
$$

where: $R_{\max }$ - maximum, and $R_{\min }$ - minimum bidirectional reflectance factors, and $R_{\max }$ and $R_{\min }$ are usually located in the azimuth of solar principal plane. In vegetation $R_{\max }$ is associated with hotspot, while $R_{\min }$ is close to nadir in the foreward scattering direction (Sandmeier and Itten, 1999). The anisotropy index (ANIX) gives the amplitude of bidirectional reflectance variation for a given spectral band for a defined view azimuth plane.

\section{RESULTS AND DISCUSSION}

The BRDF of wheat crop canopy is explained in this section by shape of the BRDF, nadir normalised BRDF (Anisotropy factor) and Anisotropy index.

Hyperspectral BRDF characterises the reflection anisotropy as a function of wavelength for wheat canopy. Out of all acquired datasets, the spectrodirectional spectra corresponding to the booting growth stage (46 DAS) of wheat was considered for the discussion of the hyerspectral BRDF and ANIF characteristics of the crop canopy. In Fig. 5a, b the distance between reflectance spectra of different view zenith angles indicates spectral variability in BRDF effects.

The BRF spectra of azimuthal plane close to principal plane $\left(\varphi=11^{\circ}\right.$, Fig. 5a) show more variation with change in view zenith angles ( 0 to -60 : forward scatter direction; 0 to 60: back scatter direction), as compared to azimuthal plane close to orthogonal plane $\left(\varphi=101^{\circ}\right)$. The variation in BRF with the view zenith angle was obscured by the magnitude of the spectral reflectance factor at specific wavelength in Fig. 5a, b. Normalisation of the BRF spectra $(A N I F)$ can be useful to reveal the BRDF effects in the reflectance factors at different wavelengths. The BRDF variation as a function of wavelength can be visualised by wavelength specific anisotropic factors for different view zenith angles (Fig. 5c, d). Anisotropic factors $(A N I F)$ more clearly illustrate the BRDF effect with view zenith angles. The spectral dependence of the BRDF was noticeable in both the azimuthal planes but it is more pronounced in azimuthal plane close to principal plane $\left(\varphi=11^{\circ}\right)$. There was large variation in the visible part of the reflectance spectra compared to near infrared (Fig. 5c, d). Along the azimuthal plane close to principal plane (Fig. 5c), back scatter direction view angles showed higher anisotropy compared to forward scattering view angles. Similar results are reported by Sandmeier et al., 1998a; Camacho de-Coca et al., 2001; and Beisl, 2001; for grass, agricultural crops and soils targets. As the exact orthogonal plane separates back scatter and forward scatter direction, the plane close to it did not reveal clear difference in anisotropy factors with view zenith angles. The reduction of the expression of the anisotropy in near infrared was due to the higher multiple scattering with low absorbance in near infrared portion of the spectra (Feingersh et al., 2005, 2010; Sandmeier et al., 1998a, b). Thus, BRDF effect is not constant for all the spectral wavelengths and requires to consider the effect as band specific.

The use of three dimensional diagrams based on a polar coordinate system is a common way to plot BRDF (Sandmeier, 2000). As BRDF effects are quasi-symmetrical to the solar principal plane (azimuthal plane involving solar azimuth), the coordinate system referred to solar principal plane instead of true north. The BRDF at four wavelengths, viz. 450, 550, 680, and $800 \mathrm{~nm}$, were considered as representative for blue, green, red and near infrared bands, respectively. These representative wavelengths are presented as dashed vertical lines in Fig. 5. The anisotropy factors 

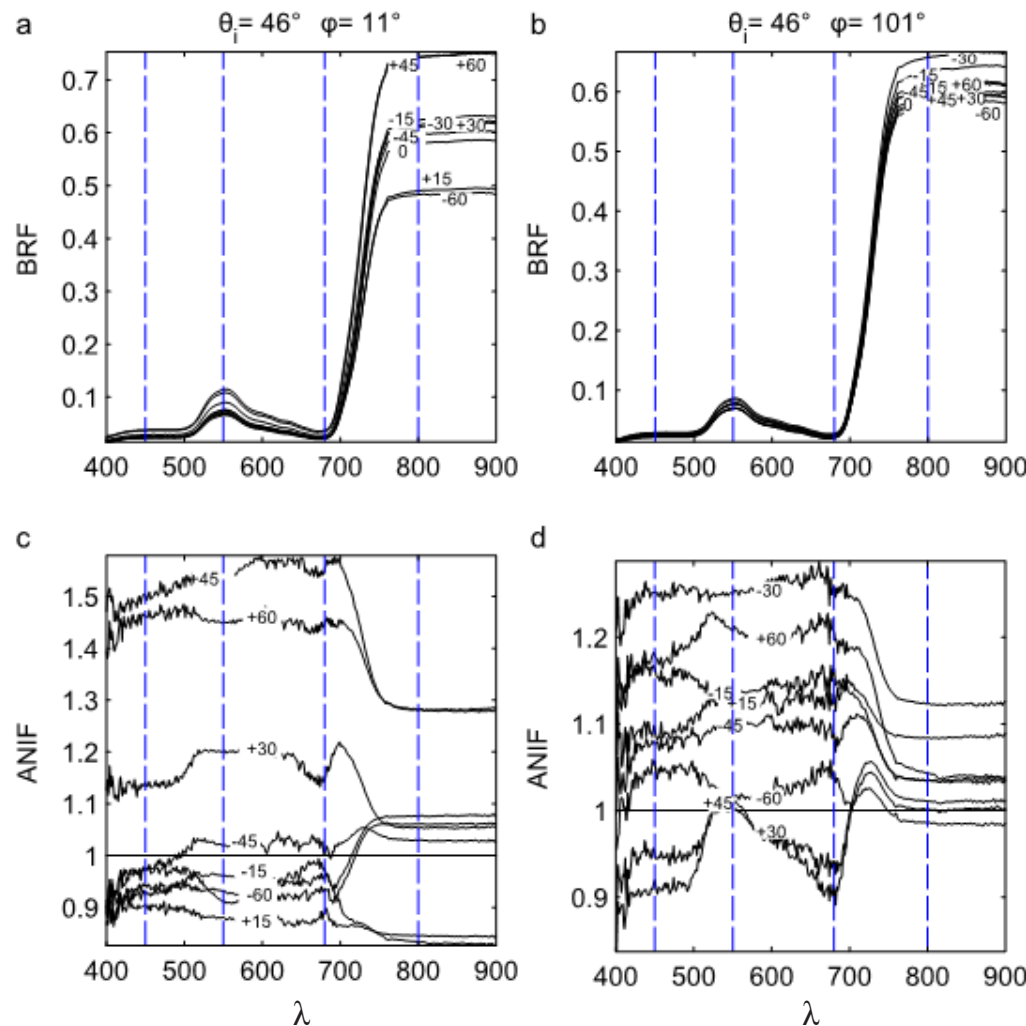

Fig. 5. Bidirectional reflectance factor and $A N I F$ at different view zeniths along azimuthal plane close to principal plane (a and c) and orthogonal plane ( $b$ and $d$ ) at booting stage of wheat.

for the closest azimuth of solar principal plane and orthogonal plane (azimuthal plane at right angle to solar principal plane) were plotted adjacent to BRDF graphs. Anisotropy profile curves for these azimuths were also plotted by polynomial fitting to generalise the anisotropic variation with view zenith angles for better depiction.

Illumination and view geometry effect on reflection factor are visualised in Fig. 6 for tillering stage (38 DAS). The BRDF patterns are almost identical for the blue, green and red wavelengths. The BRDF at $800 \mathrm{~nm}$ also exhibits more variation. At tillering, heterogeneous gap effects due to non-uniform growth resulted in high variation in shape for all wavelengths. The azimuth angles in the direction of backscattering showed an increase in the BRF along with increase in view zenith angles. The peak BRF value was observed at $60^{\circ}$ in the azimuthal plane $\left(\varphi=14^{\circ}\right)$ close to principal plane in all wavelengths. As the reflectance cannot be measured at the sensor position where hotspot occurs (solar angles exactly coincides with sensor angles i.e. $\varphi=0^{\circ}$ and $\theta_{r}=\theta_{i}$ ), all wavelengths showed broad hot spot signature near solar zenith angle in the azimuthal planes near to solar principal plane. For all the wavelengths BRDF showed mirror symmetry with respect to solar principal plane $\left(\varphi=0^{\circ}\right)$. Mirror symmetry in BRDF with respect to principal plane in vegetation is considered an important assumption for BRDF models (Lucht and Roujean, 2000).
Wheat at booting stage (46 DAS) revealed similar BRDF shapes as those observed in tillering stage but with prominent changes (Fig. 7). The ranges of anisotropy factor were also identical to those observed in the previous growth stage for all wavelengths. At this growth stage, highest BRF and anisotropy factor was observed at $45^{\circ}$ view zenith angle of back scatter direction in azimuthal plane close to principal plane $\left(\varphi=11^{\circ}\right)$. It is the signature of the hot spot area as the view zenith angle $\left(45^{\circ}\right)$ coincides with solar zenith angle $\left(46^{\circ}\right)$. The azimuthal plane close to orthogonal plane $\left(\varphi=101^{\circ}\right)$ revealed fewer changes with view zenith angles as compared to azimuth near to principal plane. Near infrared wavelength showed relatively less anisotropic difference compared to other wavelengths. The lowest anisotropy factors observed at $15^{\circ}$ of the azimuth close to principal plane might have resulted from exact canopy gap observed by the sensor.

During heading stage (60 DAS), BRDF showed distinct changes relative to the previous growth stages (Fig. 8). These differences in BRDF shape were in accordance with the dramatic changes in canopy structure. At this stage, heads emerged with long stalk, which led to about $30 \mathrm{~cm}$ increase in crop height compared to previous (booting) stage (Table 2). This results in canopy structure with two distinct characteristics, viz. upper part with sparse canopy composed of heads and stalks, while lower part is composed of dense foliage. Increase in LAI and leaf angle also indicates a drastic change in canopy structure, where canopy 

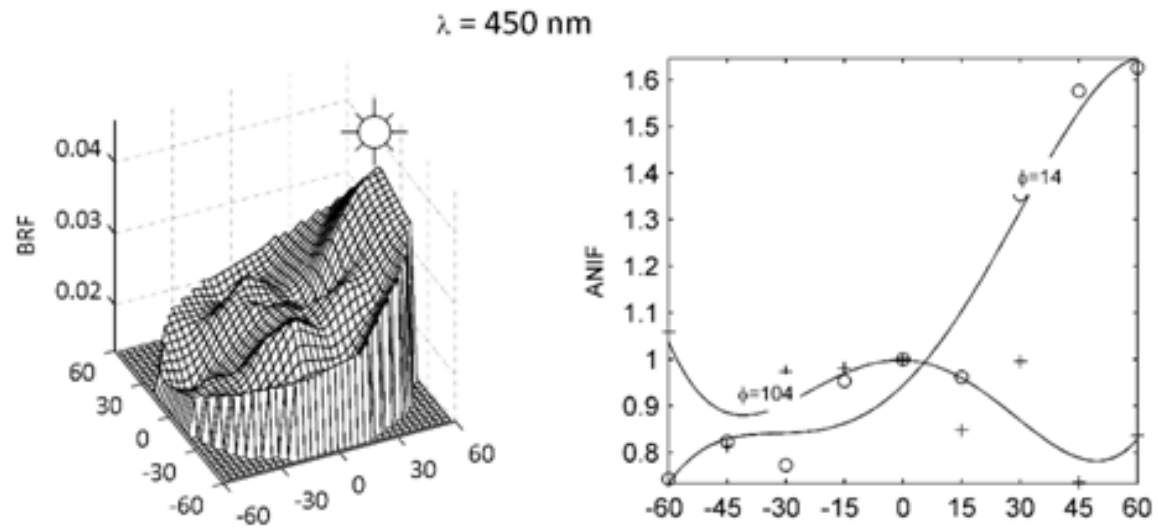

$\lambda=550 \mathrm{~nm}$
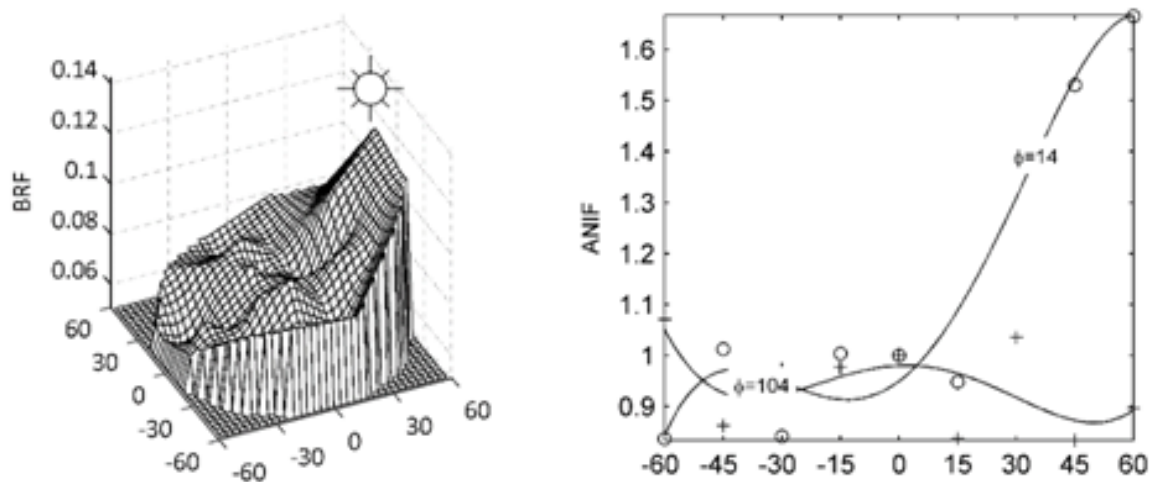

$\lambda=680 \mathrm{~nm}$
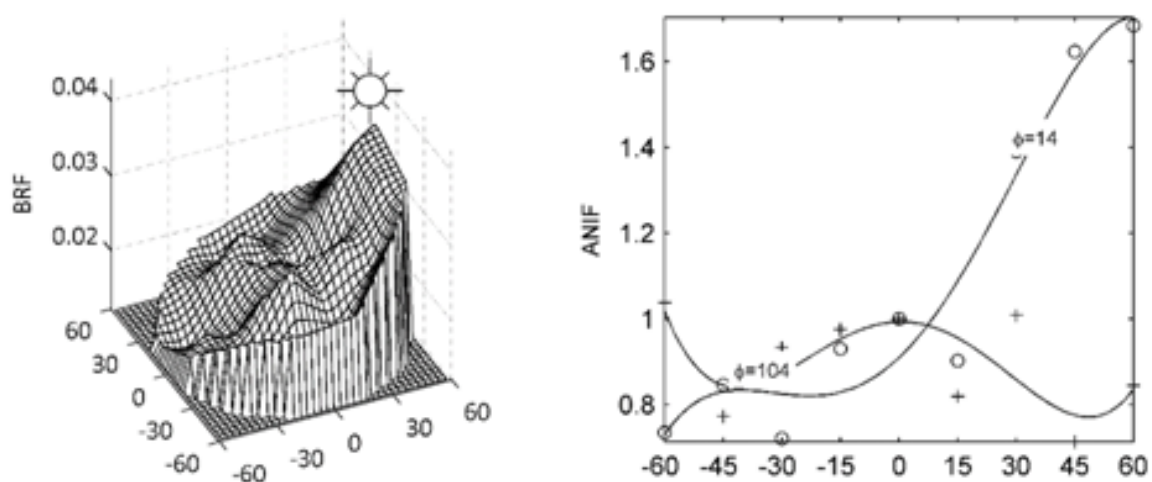

$\lambda=800 \mathrm{~nm}$
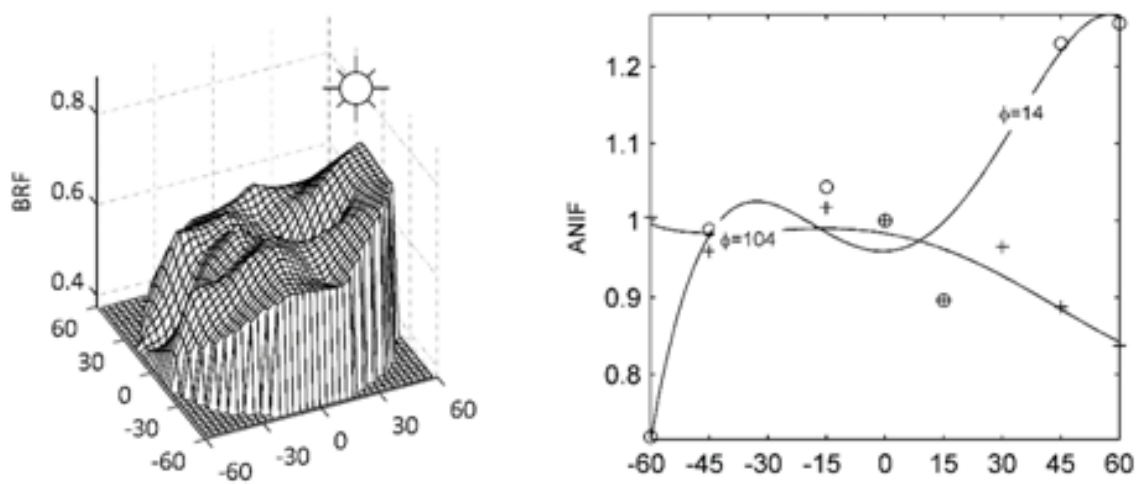

Fig. 6. BRDF and Anisotropy factor of the wheat canopy during tillering stage (38 DAS), under $46^{\circ}$ solar zenith angle $\left(\theta_{i}\right)$. The view zenith angles are on X-Y plane of BRDF plots and on X axis of $A N I F$ plots. 

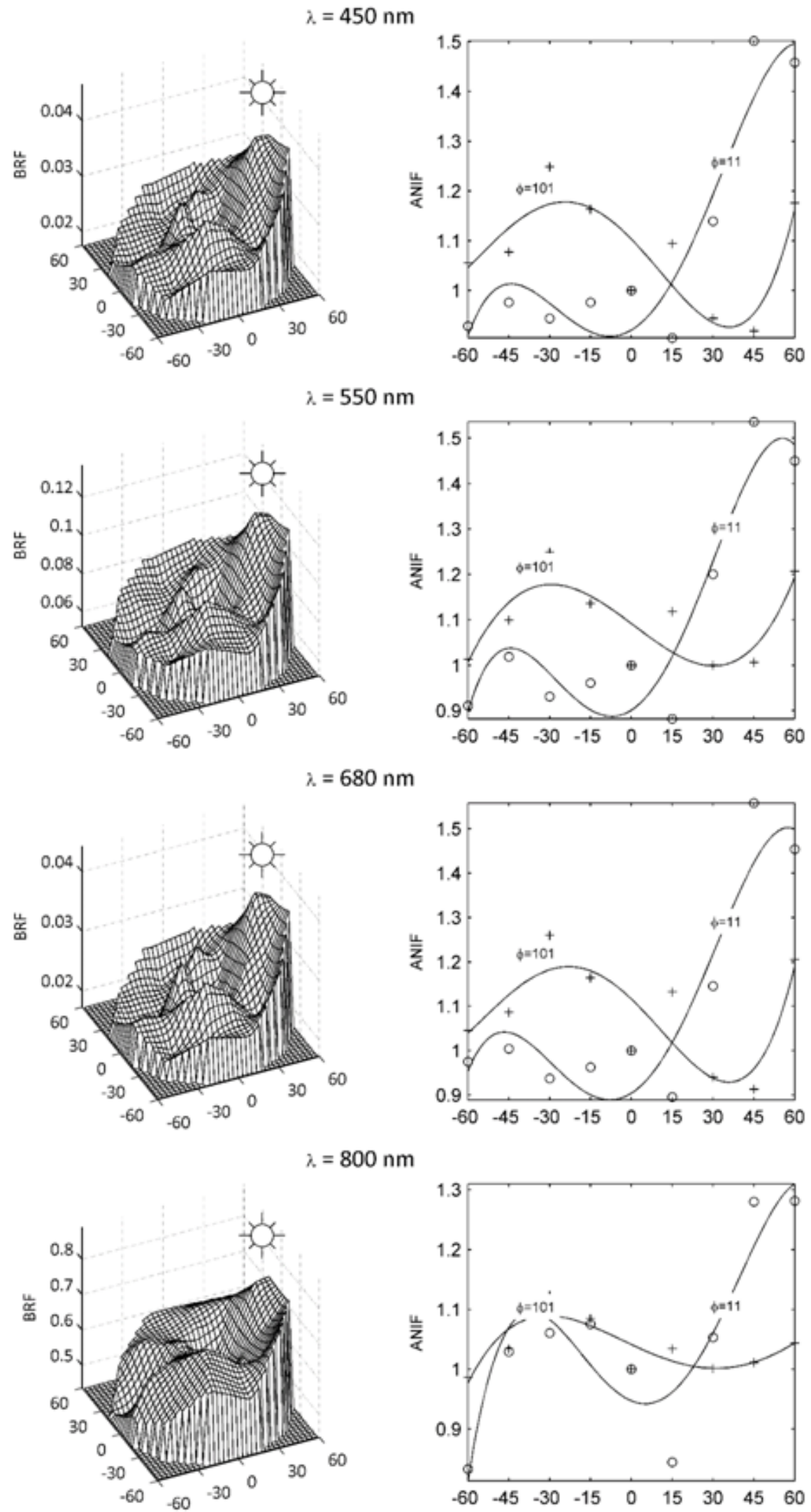

Fig. 7. BRDF and Anisotropy factor of the wheat canopy during booting stage (46 DAS), under $46^{\circ}$ solar zenith angle $\left(\theta_{i}\right)$. The view zenith angles are on X-Y plane of BRDF plots and on X axis of $A N I F$ plots. 

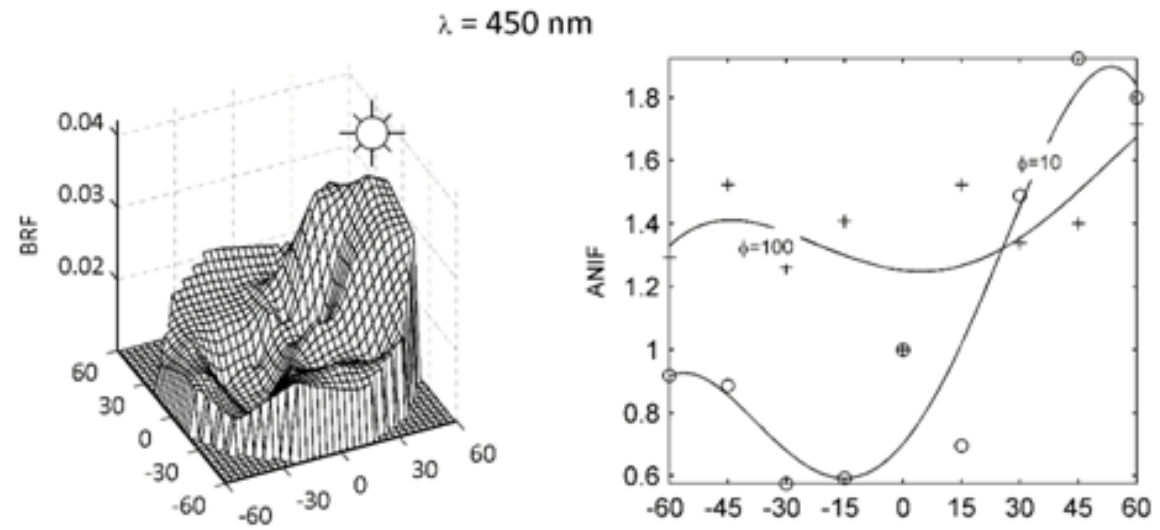

$\lambda=550 \mathrm{~nm}$
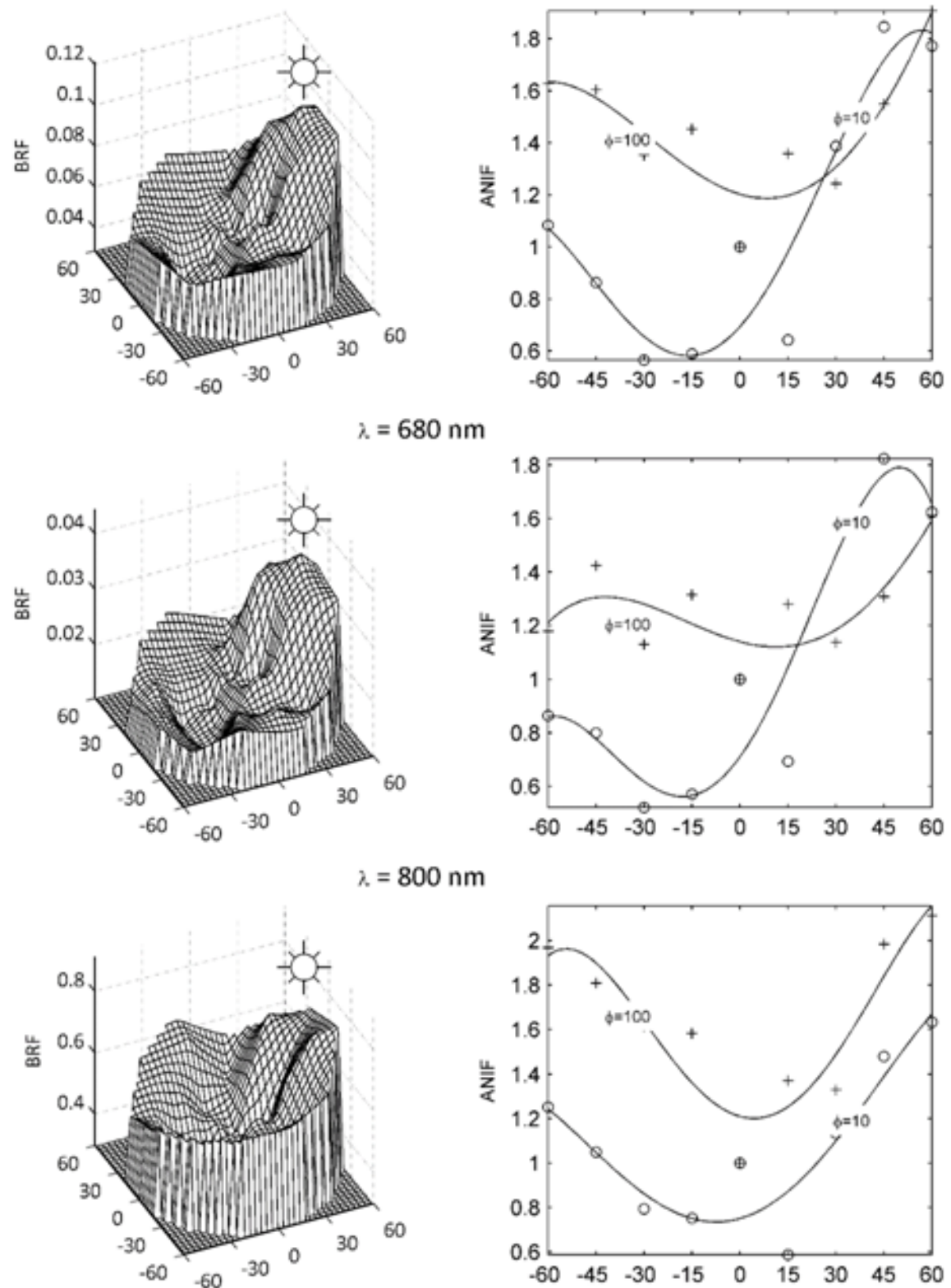

Fig. 8. BRDF and Anisotropy factor of the wheat canopy during heading stage (60 DAS), under $44^{\circ}$ solar zenith angle $\left(\theta_{i}\right)$. The view zenith angles are on X-Y plane of BRDF plots and on X axis of $A N I F$ plots. 
height increases without significant increase in foliage. The variation in BRDF decreased with small changes in view zenith angles, though anisotropic factors magnitude was found to be greater than in the previous stages. Reflectance anisotropy was more pronounced for near infrared band. Broad hot spot signatures were prominent in visible bands, and less featured in near infrared. The BRDF shape and ANIF curve profiles of visible wavelengths showed bowl shape, centred near $-15^{\circ}$ in azimuth near principal plane $\left(\varphi=10^{\circ}\right)$. In near infrared wavelength, bowl shape was symmetrical with respect to nadir. This bowl shaped pattern was observed because of a combination of gap and shadow effects which arise in dense erectophile canopy of wheat. At near nadir angles, the sensor measures reflectance from less illuminated lower canopy, and at high zenith angles the sensor measures reflectance from well illuminated upper canopy having less foliage. This results in gap effect, while back shadow effect occurs as in forward view angles the sensor captures reflectance from shadowed leaf surfaces. The distinct bowl shapes in BRDF produced from minimum reflectance near nadir and maximum reflectance (hot spot) in backscatter direction have been reported for dense erectopile canopies by other researchers (Coulson, 1966, Jensen and Schill, 2000, Ni et al., 1999).

At flowering, when crop canopy achieves more uniformity in height and appearance of heads, BRDF difference diminishes with small angular changes in view zenith (Fig. 9). Extended range of ANIF values compared to earlier growth stages indicates more anisotropic behaviour of wheat canopy. The signature of hot spot area was less noticeable as view and solar angles were not very close. The peak BRF and anisotropy factors of blue band and red band were recorded at $45^{\circ}$ in azimuth close to principal plane. Whereas, peak values in green band and infrared band were recorded at $60^{\circ}$ of the same plane. The lowest reflectance was found to shift slightly towards nadir in forward scatter direction, indicating increase of gap effect at this growth stage. The increase in gap effect was due to the drastically increased height of crop plants (Table 2).

Bowl shape of BRDF was not eminent for visible wavelengths at milking stage (Fig. 10), compared to vegetative and flowering growth stages. The shape was distinct in near infrared wavelength. BRF and ANIF values showed a gradual rise in values from nadir to extreme zenith angle $\left(60^{\circ}\right)$ in back scatter direction, for all wavelengths. The forward scatter angles from the orthogonal plane showed less variation in the reflectance anisotropy in visible bands, which is a result of decrease of green foliage and canopy being dominated by plant parts having low pigment concentration. The pattern of near infrared wavelength showed noticeable reflectance anisotropy for all angles.

The BRDF shapes were nearly identical for all wavelengths at late milking stage (82 DAS; Fig. 11). This was a result of significant decrease in overall pigment concentration and green foliage (by senescence) which governs the reflectance in visible wavebands. Unlike early milking stage, more azimuthal planes near solar principal plane showed a systematic rise in BRF with increase in view zenith angle towards back scatter direction. The lowest reflectance shifted to forward scatter angles, indicating an influence of the back shadow effect. The near infrared wavelength was still found to be dominated by gap and showed the lowest reflectance at nadir.

At dough stage, pigment concentration and green foliage lowered further, compared to milking stage. In this stage all wavelengths show almost identical BRDF shape with different degree of anisotropy (Fig. 12). The gap effect dominates, with the lowest reflectance at nadir in all the wavelengths. This might be because of low foliage leading to a fraction of soil being observed at nadir. The BRF and anisotropy factor showed gradual increase from nadir to extreme angle $\left(60^{\circ}\right)$ in back scatter direction. BRDF patterns were similar to late milking stage, with more heterogeneity. This heterogeneity arises at this stage as a result of disturbed canopy by wind and lodging of some plants. Wheat lodging and disturbed canopy at this stage occur because of the weight of grain filled heads and weak shallow roots.

Reflection anisotropy of the surface can be described by a single quantity using the anisotropy index (ANIX). The $A N I X$ versus wavelength at different growth stages of wheat are depicted in Fig. 13. Wheat canopy $A N I X$ values are in accordance to the result of Sandmeier and Deering, 1999, where they reported high ANIX associated with erectophile canopy.

In all growth stages, the visible bands show more anisotropy than the near infrared. This is in agreement with anisotropy factor results, as visible bands are high absorption bands where multiple scattering is less and exhibits more anisotropy. The spectral variability in anisotropy index is also very high in the visible part of the spectrum, while the least in near infrared. Early growth stages (tillering and booting) showed the lowest reflection anisotropy with lower range of $A N I X$ (1.5-2.3). The anisotropy index of booting stage is slightly lower than in tillering stage, which might be because of more uniformity in canopy structure achieved after the completion of tillering. Heading, flowering and early milking stage reveal less anisotropic difference among them, with $A N I X$ range between 3 and 4 for the visible part and from 2.4 to 2.9 for the infrared part of the spectra. Maximum ANIX is at late milking stage, where $A N I X$ ranges of visible and infrared wavelengths are 4.2 to 4.7 and 3.1 to 4 , respectively. This indicates that late milking is the stage where the canopy behaves as the roughest surface, with fully grown healthy crop plants. Anisotropy index was lowered during the dough stage, with high spectral variability (2.7-3.7 ANIX for visible and 2.6-3.3 ANIX for infrared). At this growth stage, red and blue bands show distinct decrease in anisotropy as a result of decrease in pigments concentration and 

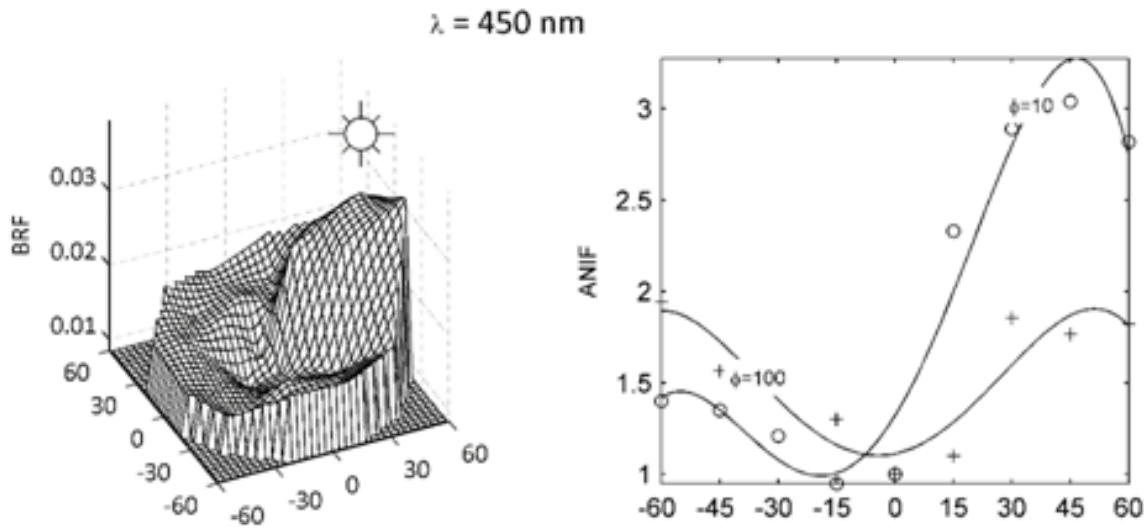

$\lambda=550 \mathrm{~nm}$
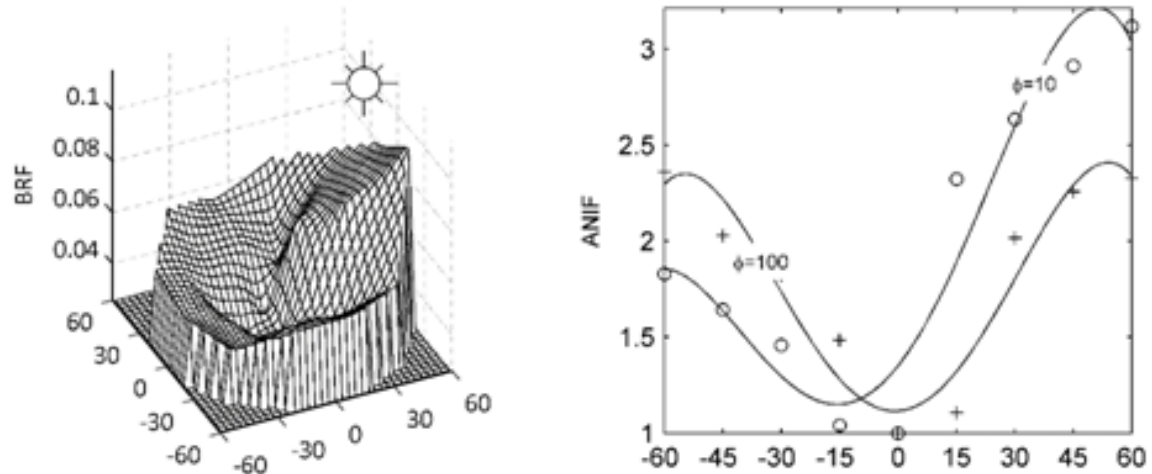

$\lambda=680 \mathrm{~nm}$
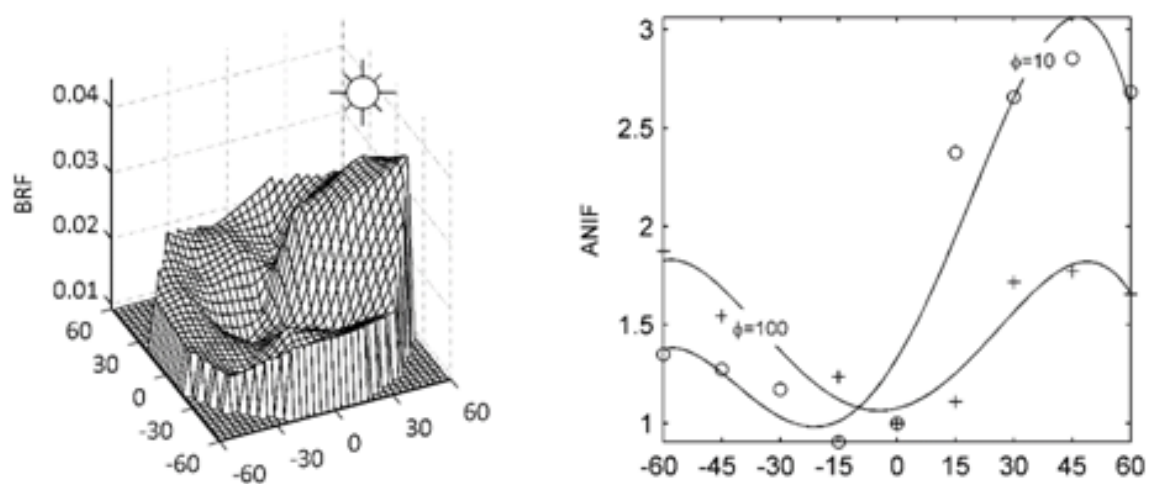

$\lambda=800 \mathrm{~nm}$
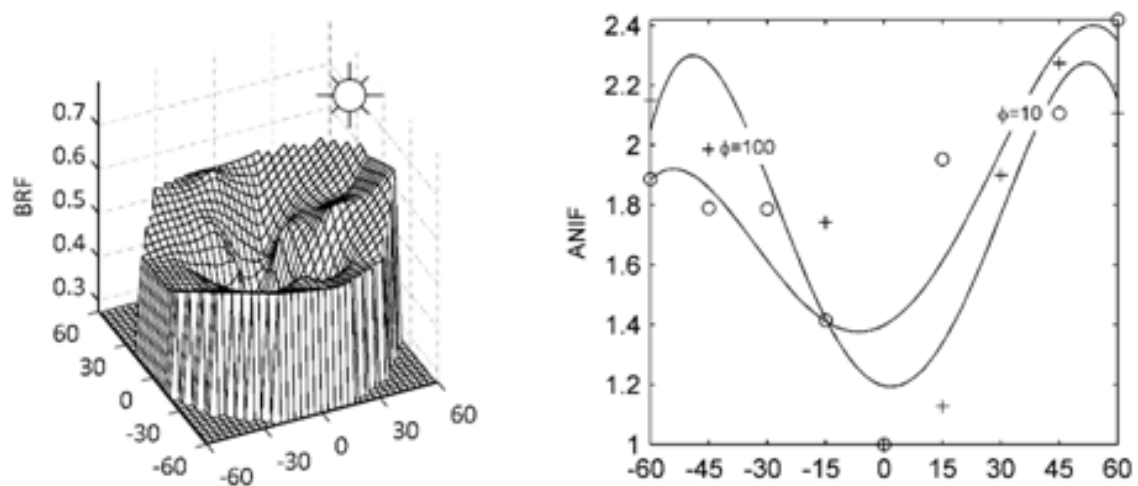

Fig. 9. BRDF and Anisotropy factor of the wheat canopy during flowering stage (66 DAS), under $42^{\circ}$ solar zenith angle $\left(\theta_{i}\right)$. The view zenith angles are on X-Y plane of BRDF plots and on X axis of $A N I F$ plots. 

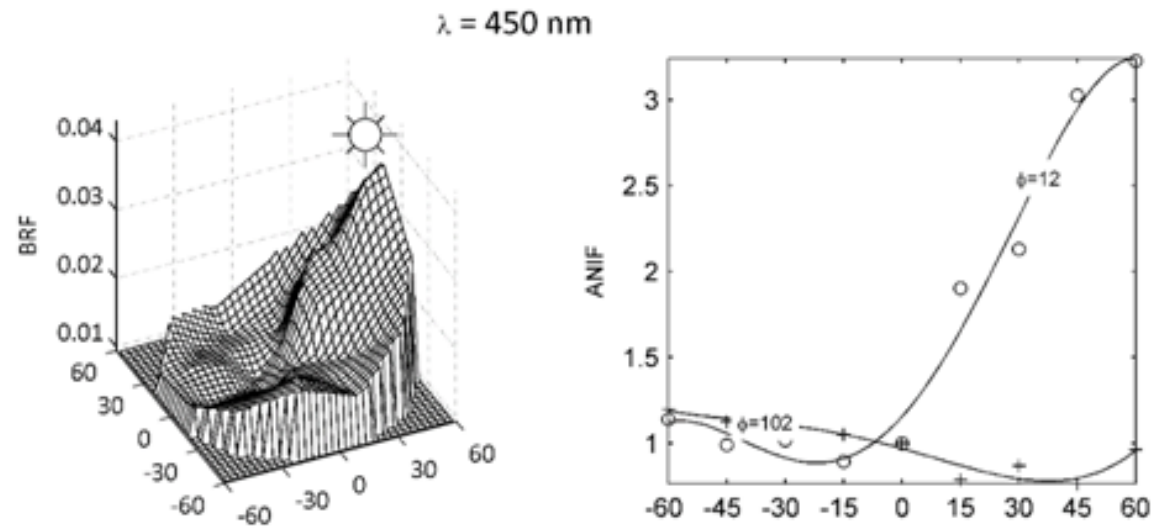

$\lambda=550 \mathrm{~nm}$
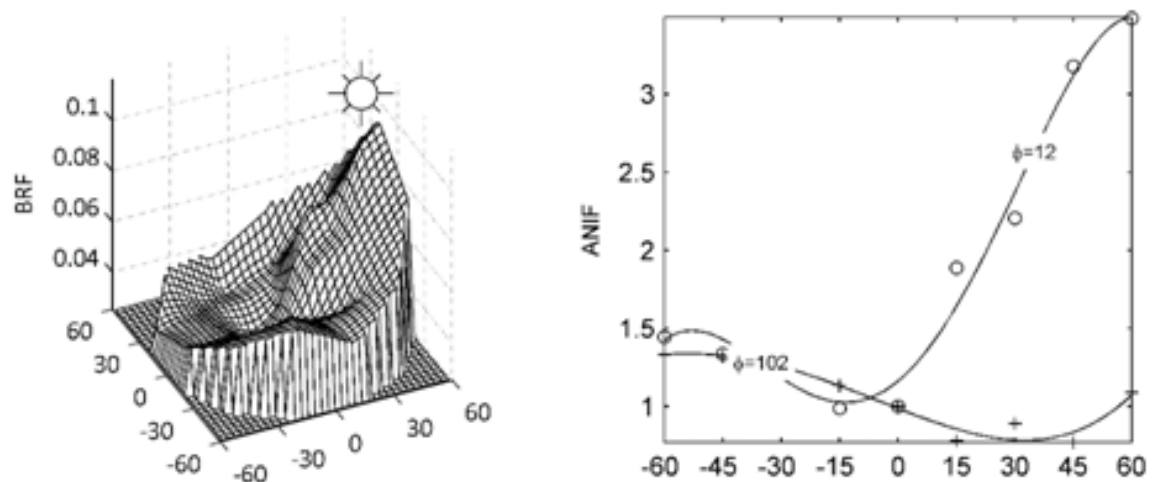

$\lambda=680 \mathrm{~nm}$
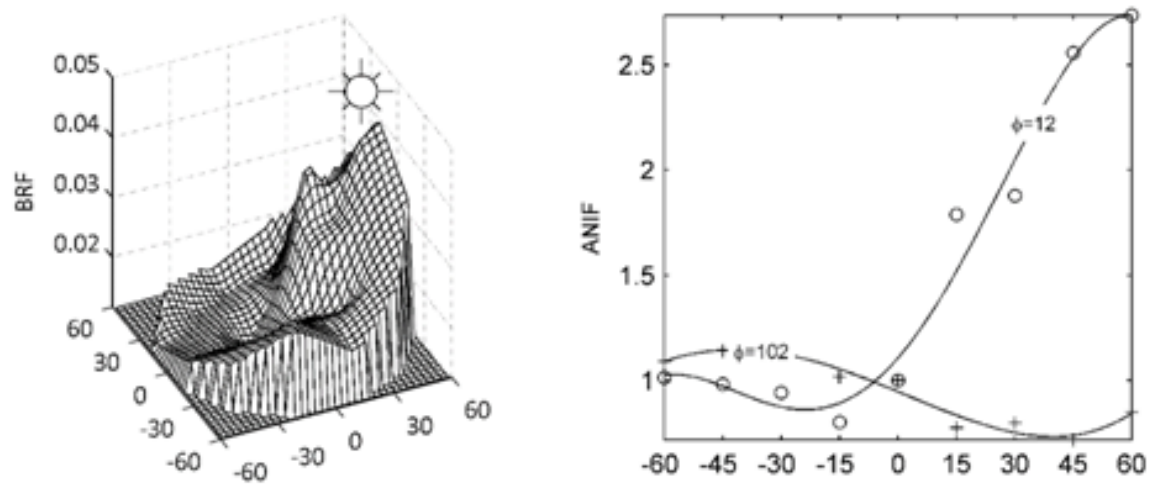

$\lambda=800 \mathrm{~nm}$
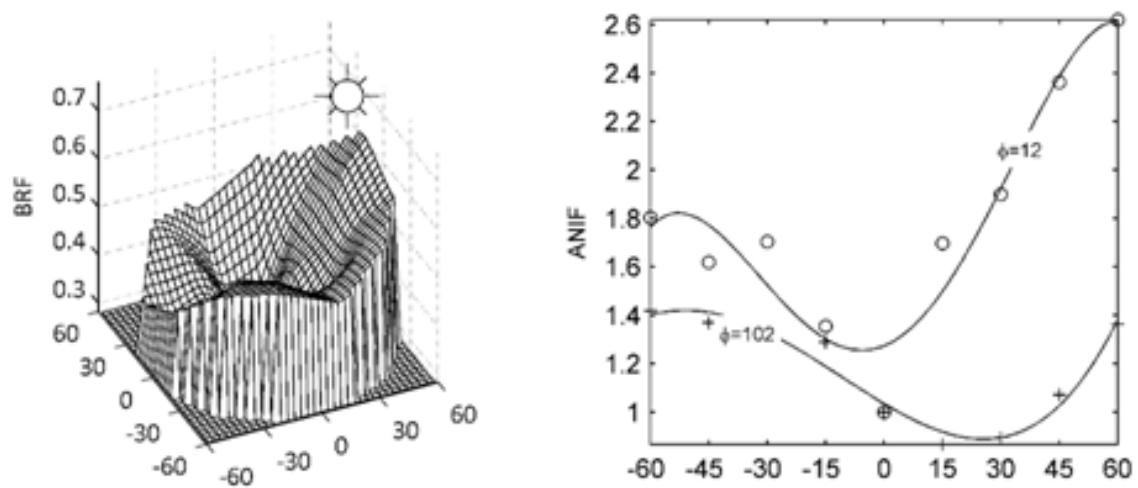

Fig. 10. BRDF and Anisotropy factor of the wheat canopy during milking stage (74 DAS), under $41^{\circ}$ solar zenith angle $\left(\theta_{i}\right)$. The view zenith angles are on X-Y plane of BRDF plots and on X axis of $A N I F$ plots. 

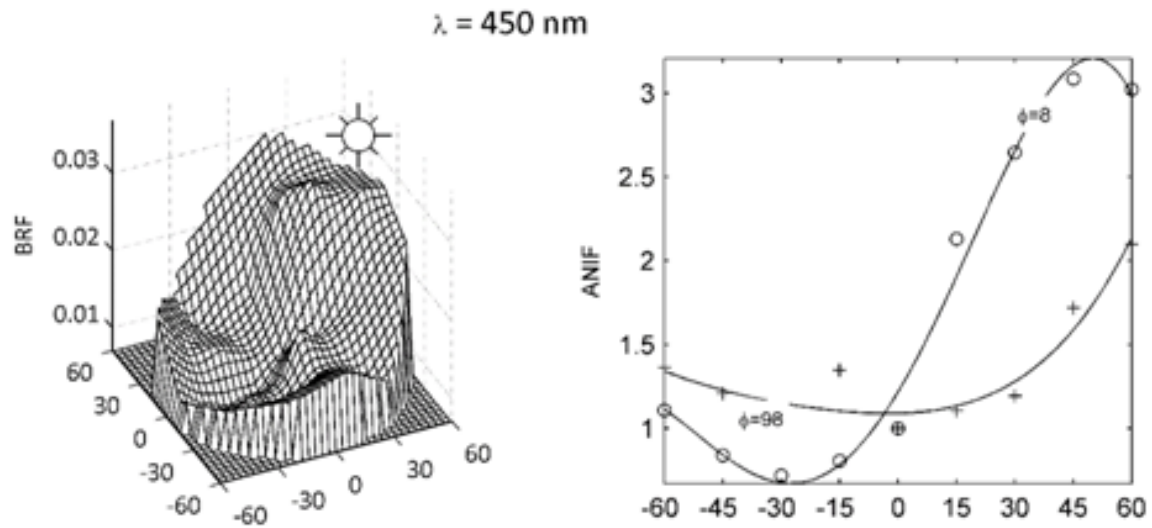

$\lambda=550 \mathrm{~nm}$
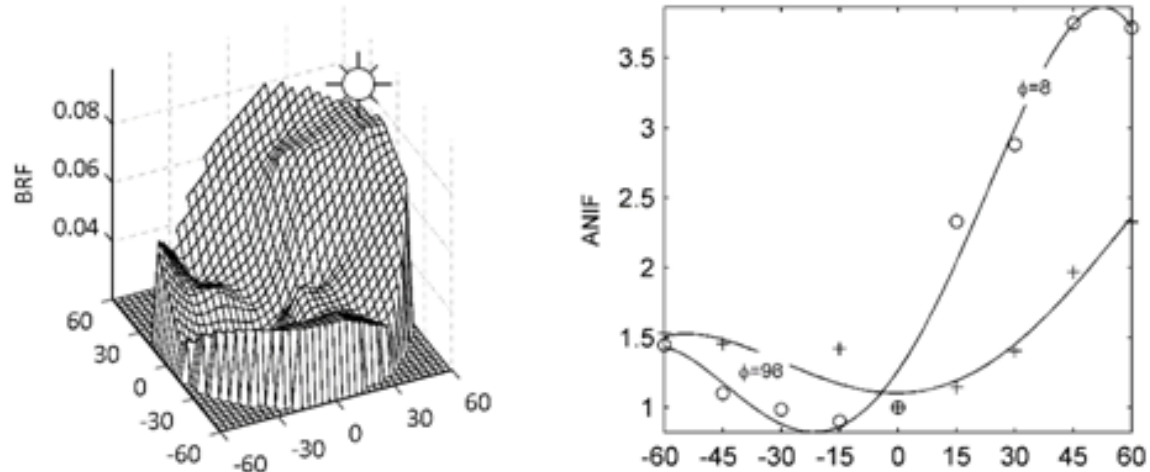

$\lambda=680 \mathrm{~nm}$
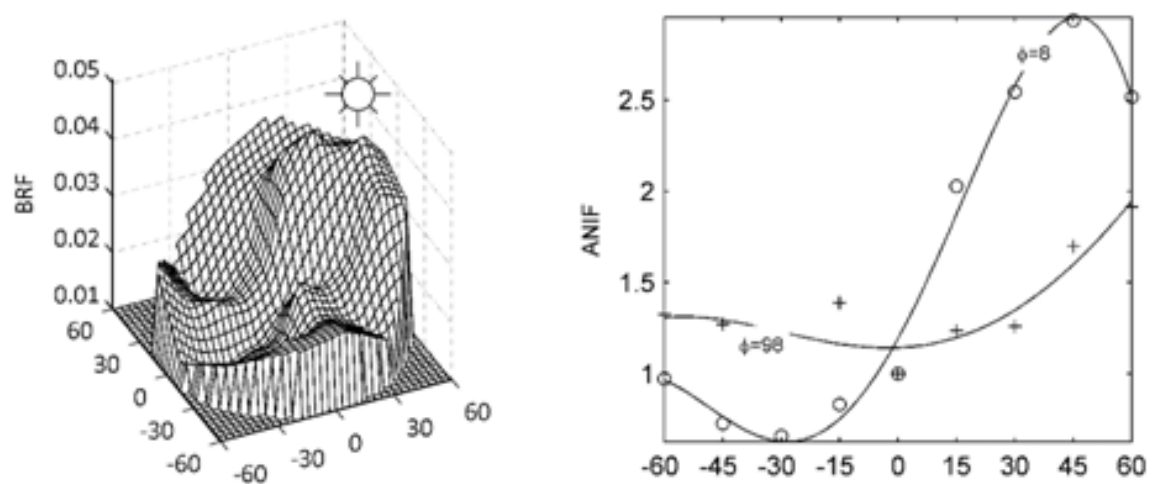

$\lambda=800 \mathrm{~nm}$
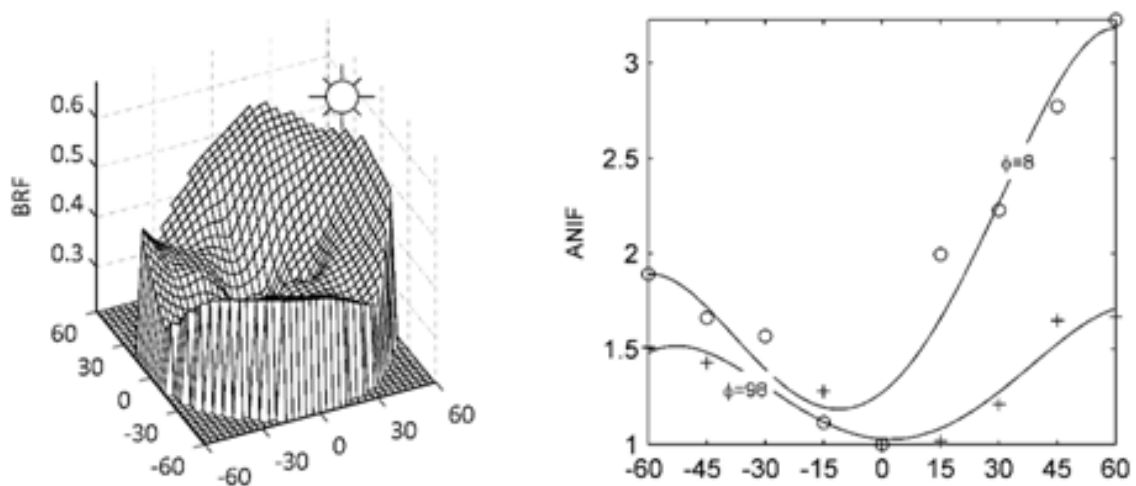

Fig. 11. BRDF and Anisotropy factor of the wheat canopy during late milking stage (82 DAS), under $39^{\circ}$ solar zenith angle $\left(\theta_{i}\right)$. The view zenith angles are on $\mathrm{X}-\mathrm{Y}$ plane of BRDF plots and on $\mathrm{X}$ axis of $A N I F$ plots. 

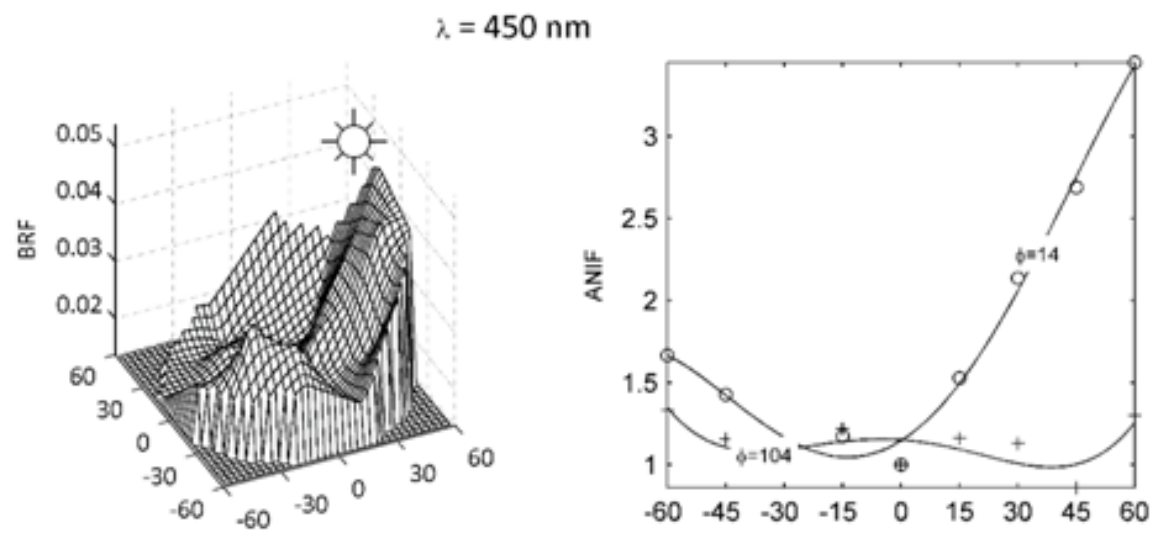

$$
\lambda=550 \mathrm{~nm}
$$
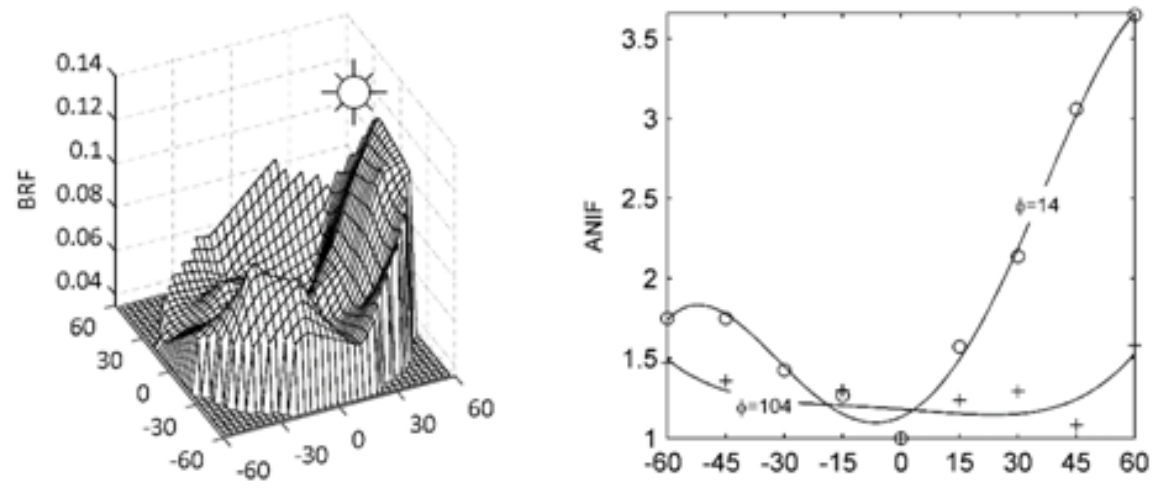

\section{$\lambda=680 \mathrm{~nm}$}
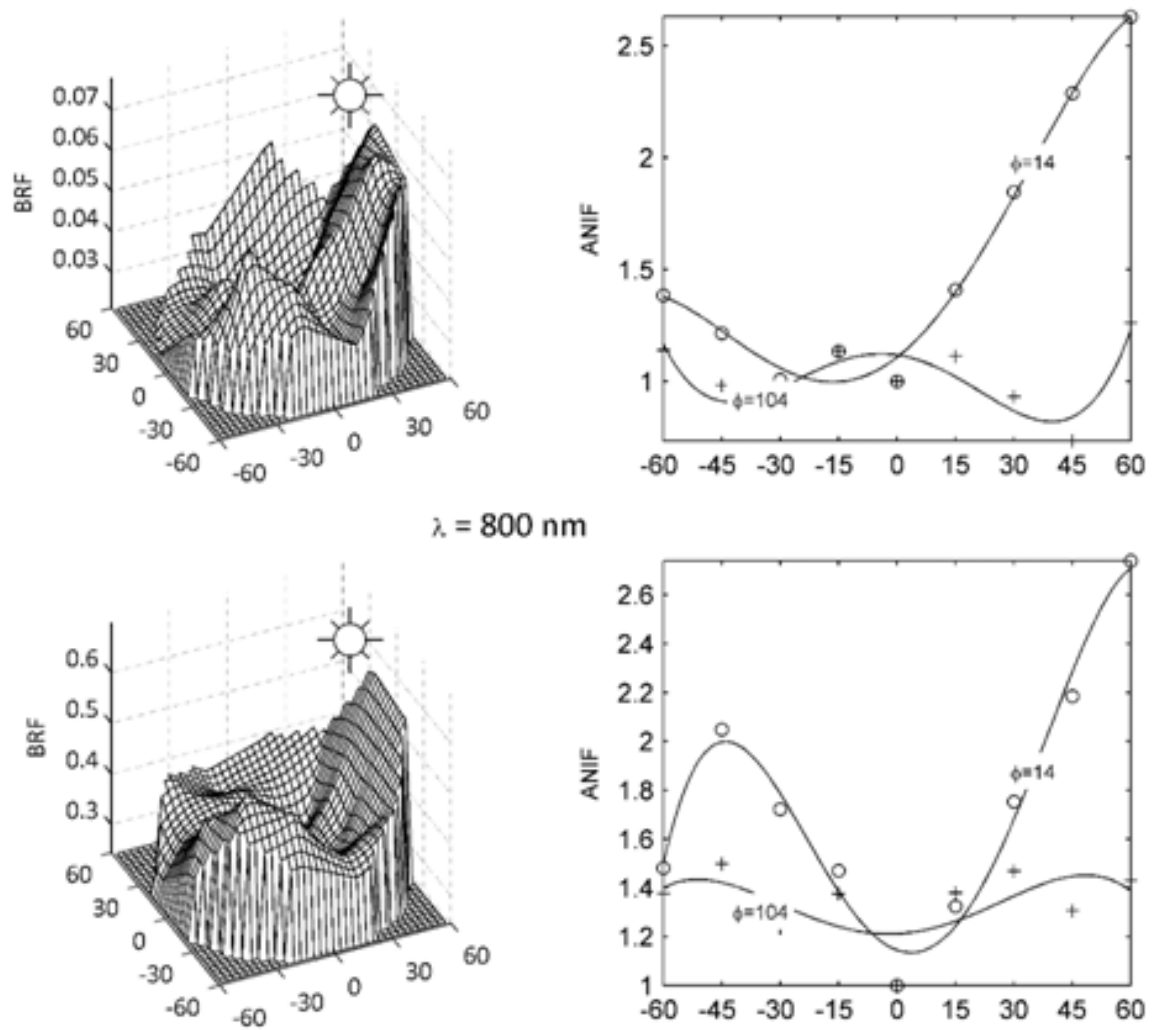

Fig. 12. BRDF and Anisotropy factor of the wheat canopy during dough stage (89 DAS), under $36^{\circ}$ solar zenith angle $\left(\theta_{i}\right)$. The view zenith angles are on X-Y plane of BRDF plots and on X axis of $A N I F$ plots. 


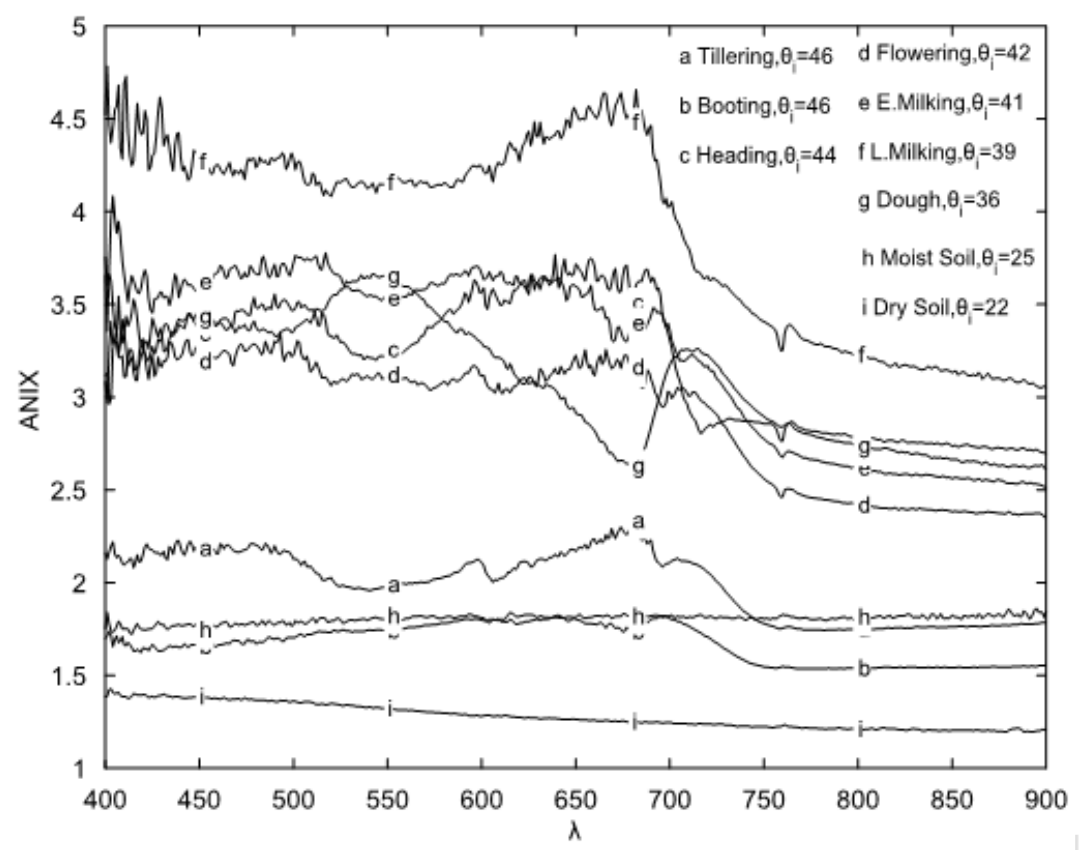

Fig. 13. Wavelength specific anisotropy index for different wheat growth stages and soils.

green foliage. Besides, high anisotropic variation arose due to disturbed canopy structure. Thus, wheat canopy exhibits large variation in BRDF effects in reflectance with phenological growth stages and with spectral bands.

\section{CONCLUSIONS}

1. Anisotropic factors clearly reveal spectral dependence of bidirectional reflectance distribution function in wheat canopy, which is more pronounced near the principal plane. Thus, reflectance anisotropy is not constant for all the spectral wavelengths and requires to consider the effect as being band specific.

2. In bidirectional reflectance distribution function shapes, broad hot spot signature is noticeable in reflectance of wheat canopy whenever view and solar angles are close. The bidirectional reflectance distribution function of early growth stages does not show the bowl shaped pattern as the canopy is more horizontally distributed. As the crop canopy achieves more uniformity in height and heads appear at booting to flowering growth stages, distinct changes occur in the function because of the gap and shadow effects. The function clearly reveals the bowl shape during heading to early milking growth stages of the crop. Late milking stage showed less pronounced gap and shadow effects compared to earlier growth stages. The shape of the function at dough stage was uneven because of disturbance and lodging of some crop plants.

3. In near infrared, wheat canopy expressed less pronounced reflectance anisotropy because of higher multiple scattering in the band.
4. The anisotropy index revealed that the wheat canopy exhibits large variation in reflectance anisotropy with phenological development which is also spectral dependent.

Conflict of interest: The Authors do not declare conflict of interest.

\section{REFERENCES}

Beisl U., 2001. Correction of bidirectional effects in imaging spectrometer data. Ph.D. Thesis. Remote Sensing Series, 37, RSL, University of Zurich, Switzerland.

Bourgeois C.S., Ohmura A., Schroff K., Frei H.J., and Calanca P., 2006. IAC ETH Goniospectrometer: A tool for hyperspectral HDRF measurements. J. Atmosphere Oceanic Technol., 23(4):573-584. DOI: 10.1175/JTECH1870.1

Camacho De-Coca F., Gilaber, M.A., and Melia J., 2001. Bidirectional reflectance factor analysis from field radiometry and the HyMap data. Proc. Final Results Workshop on DAISEX (Digital AIrborne Spectrometer EXperiment), ESA SP-499, ESTEC, March 15-16, Nordwijk, European Space Agency Paris, France.

Coulson K.L., 1966. Effects of reflection properties of natural surfaces in aerial reconnaissance. Applied Optics, 5, 905917. DOI: 10.1364/AO.5.000905

Deering D.W. and Eck T.F., 1987. Atmospheric optical depth effects on angular anisotropy of plant canopy reflectance. Int. J. Remote Sensing, 8, 893-916. DOI:10.1080/ 01431168708948697

Feingersh T., Ben-Dor E., and Filin S., 2010. Correction of reflectance anisotropy: a multi-sensor approach. Int. J. Remote Sensing, 31(1), 49-74. DOI:10.1080/01431160902882520

Feingersh T., Dorigo W., Richter R., and Ben-Dor E., 2005. A new model-driven correction factor for BRDF effects in 
HRS data. 4th EARSeL Workshop on Imaging Spectroscopy, (Eds B. Zagajewski and M. Sobczak), April 27-29, Warsaw, Poland.

Gutman G., 1987. The derivation of vegetation indices from AVHRR data. Int. J. Remote Sensing, 8, 1235-1243. DOI: $10.1080 / 01431168708954768$

Jackson R.D., Teillet P.M., and Slater P.N., 1990. Bidirectional measurements of surface reflectance for view angle corrections of oblique imagery. Remote Sensing of Environment. 32, 189-202. DOI: 10.1016/0034-4257(90)90017-G

Jensen J.R. and Schill S.R., 2000. Bidirectional reflectance distribution function (BRDF) characteristics of smooth cordgrass (Spartina alterniflora) obtained using a sandmeier field goniometer. Geocarto Int., 15, 21-28. DOI: 10.1080/ 10106049908542149

Landis B. and Aber J.S., 2007. Low-cost field goniometer for multiangular reflectance measurements. Emporia State Research Studies, 44(1), 1-6.

Lobell D.B., Asner G.P., Law B.E., and Treuhaft R.N., 2002. View angle effects on canopy reflectance and spectral mixture analysis of coniferous forests using AVIRIS. Int. J. Remote Sensing, 23(11), 2247-2262. DOI: 10.1080/ 01431160110075613

Lord D., Desjardins R.L., and Dube P.A., 1985. Influence of wind on crop canopy reflectance measurements. Remote Sensing Environ., 18, 113-123. DOI:10.1016/0034-4257 (85)90042-2

Lucht W. and Roujean J.L., 2000. Considerations in the parametric modeling of BRDF and albedo from multiangular satellite sensor observations. Remote Sensing Reviews, 18, 343-379. DOI: 10.1080/02757250009532395

Luo Y., Trishchenko A.P., Latifovic R., and Li Z., 2005. Surface bidirectional reflectance and albedo properties derived using a land cover-based approach with Moderate Resolution Imaging Spectroradiometer observations, J. Geophysical Res., 110, D01106, DOI:10.1029/2004JD 004741.

Middleton E.M., 1992. Quantifying reflectance anisotropy of photosynthetically active radiation in grasslands. J. Geophysical Res., 97(D17), 18,935-18,946. DOI: 10.1029/ 92JD00879

Ni W., Woodcock C.E., and Jupp D.L.B., 1999. Variance in bidirectional reflectance over discontinuous plant canopies, Remote Sensing Environ., 69(1), 1-15. DOI: 10.1016/ S0034-4257(98)00125-4

Nicodemus F.E., Richmond J.C., Hsia J.J. Ginsberg I., and Limperis T., 1977. Geometric considerations, and nomenclature for reflectance. U.S. Dept. of Commerce, NBS Monograph, Washington, DC, USA.

Roujean J.L., Leroy M., Deschamps P.Y., Podaire A., and Deschamps P.Y., 1992. Evidence of surface reflectance bidirectional effects from a NOAA/AVHRR multitemporal data set. Int. J. Remote Sensing, 13, 685-698. DOI: 10.1080/01431169208904146

Sandmeier S.R., 2000. Acquisition of bidirectional reflectance factor data with field goniometers. Remote Sensing Environ., 73, 257-269. DOI:10.1016/S0034-4257(00)00102-4

Sandmeier S.R. and Deering D.W., 1999. A new approach to derive canopy structure information for boreal forests using spectral BRDF data, Geoscience and Remote Sensing Symp., IGARSS '99 Proc. IEEE Int., Hamburg, DOI: 10.1109/IGARSS.1999.773516

Sandmeier S.R. and Itten K.I., 1999. A field goniometer system (FIGOS) for acquisition of hyperspectral BRDF data. IEEE Trans. Geoscience and Remote Sensing, 37(2), 978-986. DOI: $10.1109 / 36.752216$

Sandmeier S., Muller C., Hosgood B., and Andreoli G.,1998a. Physical mechanisms in hyperspectral BRDF data of grass and watercress. Remote Sensing of Environ., 66, 222-233. DOI:10.1016/S0034-4257(98)00060-1

Sandmeier S., Muller C., Hosgood B., and Andreoli G., 1998 b. Sensitivity analysis and quality assessment of laboratory BRDF data. Remote Sensing Environ., 64, 176-191. DOI:10.1016/S0034-4257(97)00178-8

Schopfer J., Dangel S., Kneubühler M., and Itten K.I., 2008. The improved dual-view field goniometer system FIGOS. Sensors, 8, 5120-5140. DOI:10.3390/s8085120

Sridhar V.N., Chaudhari K.N., Tripathi R., Chaurasia S., Patel N.K., Lunagaria M., Guled P., and Pandey V., 2009. Multi-Angular and Temporal Spectral Signature Study of Wheat (Triticum aestivum L.) Using a Field Goniometer. SAC/RESA/AFEG/CMD/SN/06/2009, ISRO, Ahmedabad, India.

Susaki J., Hara K., Kajiwara K., and Honda Y., 2004. Robust estimation of BRDF model parameters. Remote Sensing Environ., 89(1), 63-71. DOI:10.1016/j.rse.2003.10.004

Van Beek J., Tits L., Somers B., Deckers T., Janssens P., and Coppin P., 2016. Viewing geometry sensitivity of commonly used vegetation indices towards the estimation of biophysical variables in orchards. J. Imaging, 2, 15, DOI:10.3390/jimaging2020015

Zhang Q., Cheng Y.-B., Lyapustin A.I., Wang Y., Xiao X., Suyker A., Verma S., Tan B., and Middleton E.M., 2014. Estimation of crop gross primary production (GPP): I. Impact of MODIS observation footprint area and impact of vegetation BRDF characteristics. Agric. Forest Meteorol., 191, 51-63. DOI: 10.1016/j.agrformet.2014.02.002 